\title{
Effects of Air Temperature Fluctuations on Turnover Time of a Little Mountain Reservoir
}

\author{
Hong LI \\ School of Environmental Science and Engineering \\ Qingdao University \\ Shandong, China \\ e-mail: lihongqdu@163.com
}

\author{
Zengwen GAO \\ School of Environmental Science and Engineering \\ Qingdao University \\ Shandong, China \\ e-mail: gaozengwen@163.com
}

\begin{abstract}
Reservoirs serve a lot in solving water shortage problems. It is critical to ensure the quality in the reservoir. Turnover time is identified to influence the water quality significantly. In this study, the effect of air temperature variations on turnover time in a reservoir on Fushan Mountain (Qingdao, Shandong Province, China) has been investigated by field observations. We have monitored the temperature profiles in the reservoir during the stratification period and mixing period in continuous three years. The theoretical turnover time was also calculated. The monitored data indicated that the turnover time in 2016 was much earlier than that in other two years. The reasons for turnover time variations were studied. Ruled out the possible effects of wind, water depth and the average hypolimnion temperature, the air temperature fluctuation (affecting the epilimnion water temperature mostly) was found to be in charge of the reservoir being mixed earlier. Therefore attentions should also be focused on air temperature fluctuation in the prediction and management of seasonal stratified reservoirs.
\end{abstract}

Keywords-turnover time; reservoir; air temperature
fluctuation; water quality

\section{INTRODUCTION}

As we all know, reservoirs play an important role in water supplies, such as drinking water, fish farming and agriculture irrigation. Mixing process, as a part of physical limnology, is discussed extensively, for it together with stratification affects water quality significantly. Stratification process has been studied comprehensively, the metalimnion acts as a barrier to prevent the solute and gas exchanges between the epilimnion and hypolimnion, resulting in an anoxic condition [1] and nutrients enrichment [2] [3] in the hypolimnion normally. However, mixing process drives in the opponent direction. On the one hand it may lead to oxygen deficiency in the bulk water and aquatic organism death [4]. On the other hand, it may lead to nutrients and trace elements enriched in the upper epilimnion water [5]. In the category of mixing, turnover time is of vital importance. If the date of the fall turnover is early, productivity would be enhanced due to rich nutrients and suitable temperature [6]. Effects mentioned above make it necessary to determine the mixing time. Knowing the mixing time can help us take measures such as aeration to prevent the negative effect of mixing at a proper time. It is well accepted that temperate thermally stratified water is no mixing in summer, partial mixing in autumn and well mixed in winter. A model was set by Nürnberg [6] to predict the turnover time, which explains $67 \%-80 \%$ of variances. Although there was no improvement in the regression when the weather conditions were added, Nürnberg pointed the weather differences might account for part of the residual variation [6]. In recent years, climate changes have led to many extreme weather phenomena, such as more frequent air temperature fluctuations. The air temperature fluctuation affects the epilimnion water temperature significantly, which might trigger the mixing process of the bulk water. This paper is to compare different mixing time of a reservoir on Fushan Mountain to explore the potential effect of the air temperature fluctuation on the turnover time to assistant with management of reservoirs.

\section{METHODS}

\section{A. Area and Field Observations}

The studying area is in a reservoir on Fushan Mountain $\left(36^{\circ} 04^{\prime} \mathrm{N}\right.$ and $120^{\circ} 25^{\prime}$ E) situated in Qingdao, Shandong Province (Figure 1). The water depths were $8.8 \mathrm{~m}$ in 2014 and $5.7 \mathrm{~m}$ both in 2015 and 2016. There are no significant river inflows and outflows, therefore the main water source is the underground water. Under the influence of Fushan Mountain and a small effective fetch ( $78 \mathrm{~m}, \mathrm{SE}$ to $\mathrm{NW}$ ), effect of wind on the water motion could be ignored. According to our field observation, the water would appear to be thermally stratified in summer.

Field monitoring had been conducted at the central of the dam, where is the deepest. The temperature profiles were measured by YSI 6920 . Usually the data would be recorded every $10-20 \mathrm{~cm}$ depth. 


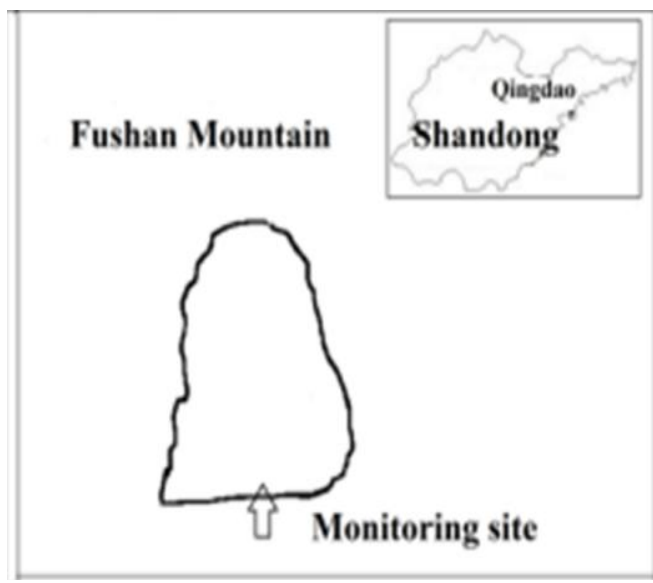

Figure 1. Map of the reservoir and the monitoring site.

\section{B. Calculation of the Turnover Time in the Reservoir}

The turnover time in the reservoir was calculated by the Eq. (1).

$\log ($ turnover time $)=2.62-0.116 \log S E+0.042 \log \bar{z}-0.002 \operatorname{lat}_{a d}(1)$

Where $S E$ is the average hypolimnion temperature; $\bar{z}$ is the mean depth of the reservoir; and the ${ }^{l a t_{a d}}$ is the adjusted latitude, calculated by Eq. (2).

$$
\text { lat }{ }_{a d}=l a t_{x}+0.01 a_{x} \times a l t
$$

${ }^{l a t_{x}}{ }_{\text {represents latitude (in decimal degrees) and }} a_{x}$ is the factor which converts $100 \mathrm{~m}$ of altitude (alt, m) into degrees of latitude at a given latitude ${ }^{x}$ (interpolated from Lewis [7]).

\section{RESUlTS AND DiscUSSION}

\section{A. Monitoring Results}

Results of the monitored temperature profiles are showed in Figure 2

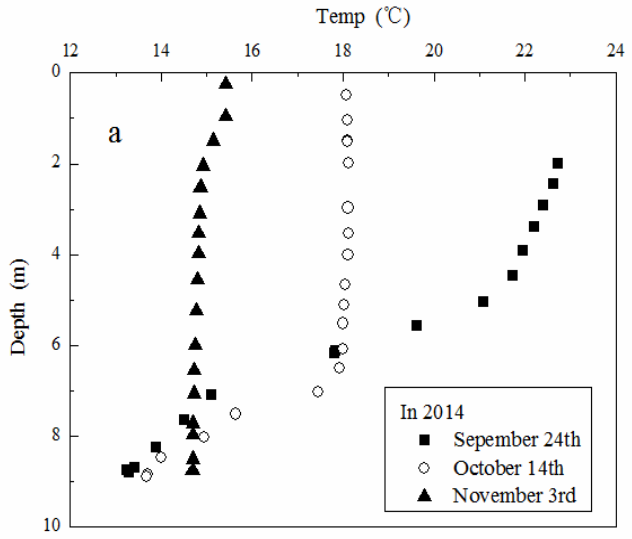

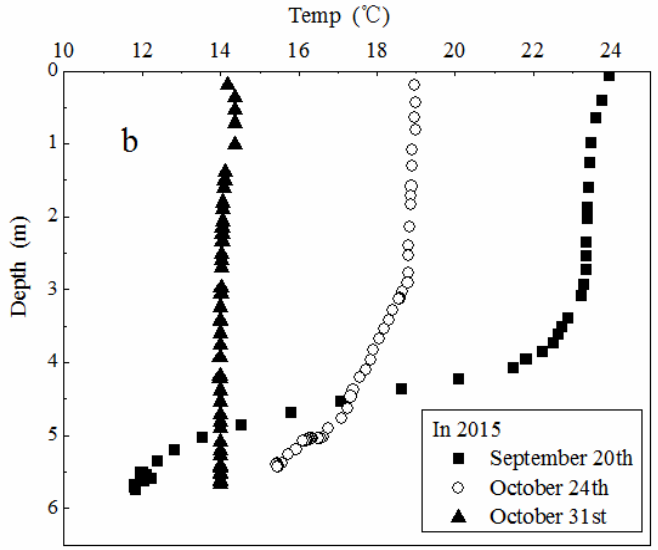

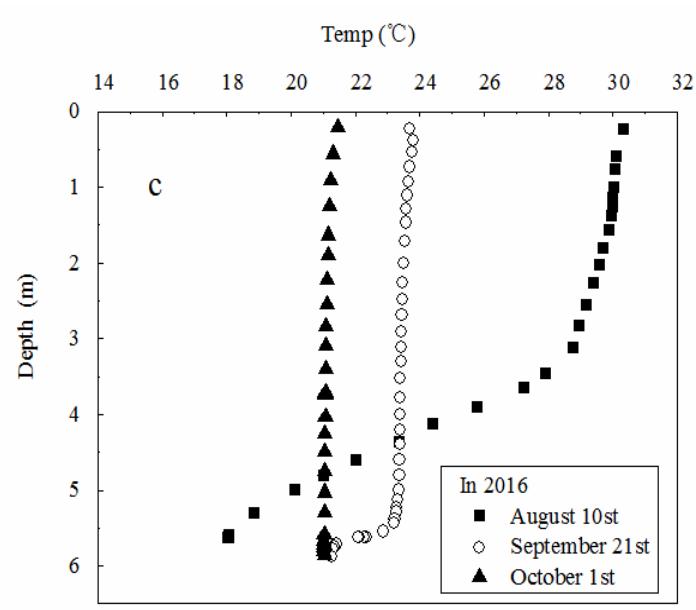

Figure 2. Temperature profiles variation of different dates in different years

It is showed that mixing time varied in years (Figure 2). It was November $3^{\text {rd }}$ in 2014, October $31^{\text {st }}$ in 2015 and September $21^{\text {st }}$ in 2016 , respectively. The reservoir was mixed completely much more earlier in 2016 than that in 2015. There are no significant variations in water depth, which is in the range of 5.6-5.7 $\mathrm{m}$ in the two years. Forces opposing stratification include wind energy and loss of heat from the surface [8]. Previous works showed wind has no effect on the water motion in the reservoir because of the small effective fetch and the influence of Fushan.

\section{B. Comparison of the Calculated Turnover Time with the Measured}

According to the model set by Nürnberg, factors of the adjusted latitude, mean water depth and the average hypolimnion temperature were considered [6]. The hypolimnion temperature was the average of temperatures in July and August. Compare the calculated turnover time in 2014 and 2015 with that measured and it could be seen that there were some days deviations ( $8 \%$ and $6 \%$, respectively) (Table I). However, the comparison in 2016 is different. The deviation (about 18\%) was too large to be acceptable. 
TABLE I. ANNUAL VARIATIONS OF THE TURNOVER TIME IN CALCULATION AND MEASUREMENT IN THE RESERVOIR

\begin{tabular}{rrrrrrr}
\hline & $\begin{array}{r}\text { Hypolimnion } \\
\text { temperature } \\
\left({ }^{\circ} \mathrm{C}\right)\end{array}$ & $\begin{array}{r}\text { Average } \\
\text { water depth } \\
(\mathrm{m})\end{array}$ & $\begin{array}{r}\text { Adjusted } \\
\text { latitude }\left(^{\circ}\right)\end{array}$ & & Turnover time & (day) \\
\cline { 5 - 6 } & 12.11 & 6.2 & 36.47 & 331 & Calculation & Measurement \\
\hline In 2014 & 12.5 & 3.8 & 36.47 & 323 & 304 \\
In 2015 & 17.5 & 3.8 & 36.47 & 311 & 264 \\
\hline In 2016 & & & & & & \\
\hline
\end{tabular}

In addition, there was no variation in the average water depth in 2014 and 2015. When the hypolimnion temperature in 2016 rose, the turnover time would be 12 days earlier than that in 2015 according to the Nürnberg's model. However, the real turnover time in 2016 was 47 days earlier than that in 2015. Therefore other factors must exist to determine the turnover time in the reservoir.

\section{Air Temperature Fluctuation Effects on Turnover Time in the Reservoir}

Ever recorded weather conditions showed the main difference lay in the atmospheric temperature (Figure 3).
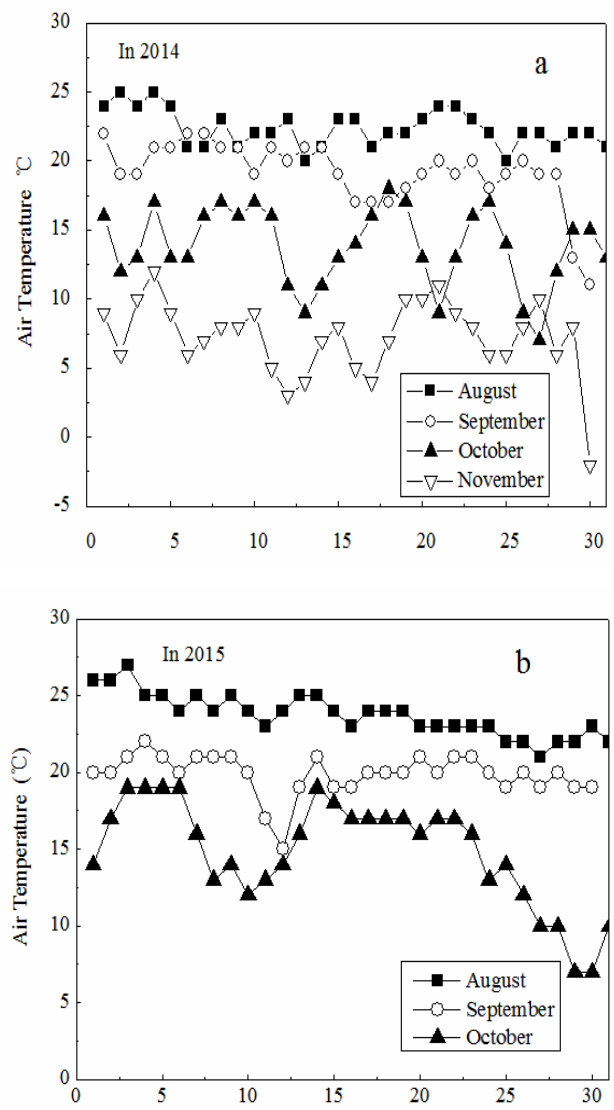

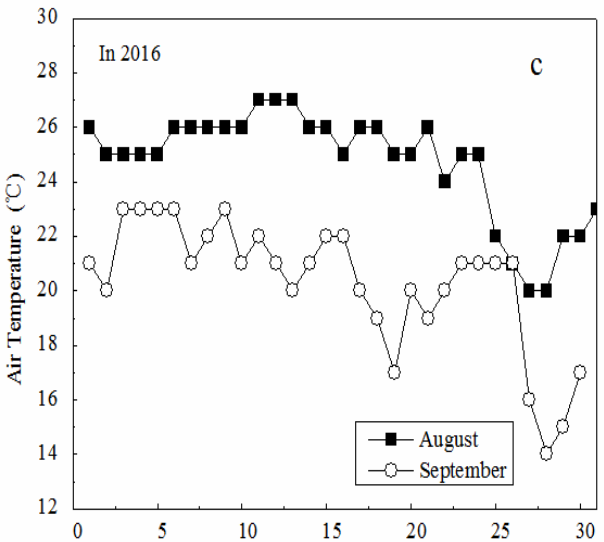

Figure 3. Time series of the minimum air temperature of different months in different years.

The air temperature in August was much higher (about $2^{\circ} \mathrm{C}$ ) in 2016 than that in 2014 and 2015. It resulted in a higher hypolimnion temperature in 2016. When the air temperature began to drop in September, the water was likely to be mixed gradually. In 2016, there was a sharp drop in the air temperature before the turnover time (Figure 2c) and it was below the hypolimnion temperature $\left(17.5^{\circ} \mathrm{C}\right)$, resulting in the completely mixing of the bulk water. In addition, cooling in a short time was able to arise the bulk water mixed due to the small surface area and water depth of the reservoir.

Mixing process of a stratified reservoir directly determines the water quality in the reservoir. Therefore to have a clearly understanding of the mixing process especially the turnover time is necessary. Many studies have been carried on and there are many models to predict the date of mixing considering different influential factors. In the model set by Nürnberg the importance of the hypolimnion water temperature was emphasized [6]. Our monitoring data of a reservoir on the Fushan Mountain showed that for the same reservoir, it may have different mixing time as a result of the air temperature fluctuation. These measurements and analysis highlighted the significance of air temperature fluctuations. When the air temperature dropped, the mixing might be triggered. And when it was below the hypolimnion temperature, the water might be mixed completely. Therefore, to predict the turnover time, attentions should be 
focused not only on the temperature in the hypolimnion but also on the air temperature fluctuation especially the episodic. The air temperature fluctuation should be taken into consideration to achieve dynamic management of the reservoir.

Further works would be done to explore the effect of water depth as well as the temperature in the hypolimnion variations on the turnover time in the thermally stratified reservoirs.

\section{CONCLUSION}

Our field monitoring showed that the turnover time in 2016 was much earlier than that in 2014 and 2015, which was abnormal. The theoretical advanced time calculated by the Nürnberg's model was 12 days in 2016 due to the variation in the hypolimnion temperature. However the measured data showed the reservoir water was mixed much earlier (47 days). Analysis indicated the main difference lay in the air temperature fluctuation.

It was proved that the episodic air temperature fluctuation with a sharp temperature drop could affect the turnover time significantly in small reservoirs. Therefore it is necessary to take the air temperature fluctuation into consideration in the management of reservoirs.

\section{ACKNOWLEDGMENTS}

This research was financed by the National Natural Science Foundation of China (No.51279075) and the National Natural Science Foundation of Shansong
(ZR2009EQ001). We are very grateful to Xie Lei, Li Yuhao, Qin Zhixin, Cheng Chen and Li Jing for their assistance with the monitoring.

\section{REFERENCE}

[1] S. Elci, Effects of thermal stratification and mixing on reservoir water quality, Limnology, 9, 135 (2008).

[2] C. H. Mortimer, The exchange of dissolved substances between mud and water in lakes, J. Ecology, 29, 280 (1941).

[3] C. H. Mortimer, The exchange of dissolved substances between mud and water in lakes, J. Ecology, 30, 147 (1942).

[4] Y. C. Wang, J. Zhu, M. Ma, C. Q. Yin, C. Q. Liu, Thermal Stratification and Paroxysmal Deterioration of Water Quality in a Canyon--Reservoir, Southwestern China (in Chinese), J. Lake. Sci, 17, 54 (2005).

[5] G. K. Nürnberg, Availability of phosphorus from iron-rich anoxic hypolimnia, Arch. Hydrobiol, 104, 459 (1985).

[6] G. K. Nürnberg, A simple model for predicting the date of fall turnover in thermally stratified lakes, Limnol. Oceanogr, 33, 1190 (1988).

[7] W. M. Lewis, A revised classification of lakes besed on mixing, Can. J. Fish. Aquat. Sci, 40, 1779 (1983).

[8] D. L. Bade, Lake Ecosystems (Stratification and Seasonal Mixing Processes, Pelagic and Benthic Coupling), Encyclopedia of Hydrological Sciences, Part 9: 108 (ed. by M.G. Anderson), John Wiley \& Sons, Chichester, UK doi: 10.1002/0470848944, hsa114 (2005). 